\title{
16 Alternative Methods of Holding and Measuring Birds
}

In some ringing manuals, other methods than what is described here as a standard methods of the bird holding, are described and shown at illustrations. Sometimes, they are recommended for general use, sometimes to perform separate measurements.

A left-hand handling is in common use as shown by figures in The Ringer's Manual (Spencer, 1972), Figure 16.1, or in Identification Guide to European Passerines (Svensson, 1992). The first method is very similar to that recommended here as the standard holding method (apart from the hand used for holding bird). The second one is completely different, as the bird is handled in the opposite direction, with the bill to the wrist. According to these methods of holding, standard descriptions of some measurements are adapted and given below.

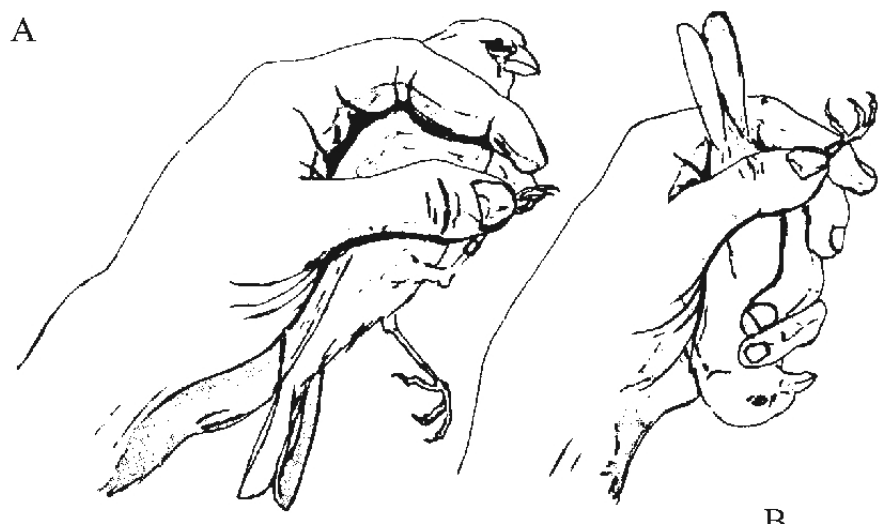

$\mathrm{B}$

Figure 16.1: Handling the bird - two methods after Spencer (1972) drawing.

Comments: The left-hand holding of bird derives from an old custom of ringers, even those working at the bird stations, that the same person handles the bird, rings and measures, and writes data into ringing form. When one uses this method, there is no necessity to move the bird from one hand to another when writing data: most people are right-handed and they write using their right hand "so, the right hand should be free of the bird". In a modern way of work, in a team, there is no such necessity anymore, and the speed of work can be much higher than before. As it was stressed in the description of the standard holding, the right-hand holding allows manipulation of the bird more quickly and safely to the bird since the right hand "feels" bird body much better. 
Wing-length measurement. As the method of wing-length measurement used earlier, unflattened wing, is nearly not in use any more it will not be described here. It was rejected from the practice, as its results are not enough repeatable and possible to be standardised.

Wing-length flattened chord measurement after The Ringer's Manual (Spencer, 1972). This is basically the method described in The Handbook of British Birds (Witherby et al., 1938-41): “The ruler is slipped under the naturally flexed (but unspread) wing and the carpal joint is pressed gently against the stop. The wing is then flattened against the rule by firm but gentle controlled pressure on the median or greater coverts. This removes some or all of the camber along and across the wing, but the primaries are not straightened, so that they lie along the rule with their normal lateral curvature undisturbed".

Comments. Although this method is capable of producing a reliable measurement of a wing, it should be noted that variation in the degree of pressure applied in holding the wing to the ruler would produce small differences in the measurements obtained. For this reason, the results obtained are less reproducible between ringers or, sometimes, even by the ringer himself. Nor is the method any more successful than method of unflattened wing at allowing unavoidable alteration of lateral curvature.

Wing-length maximum chord measurement after The Ringer's Manual (Spencer, 1972): "In this method, in addition to applying firm pressure on the wing as in method "flattened wing" to remove all camber along and across the wing, the lateral curvature is also eliminated as far as possible. This is done by sliding the wing forward along the rule until it meets the stop, straightening the bastard wing so that it falls into line, as far as possible, with the longest primary, and then straightening and extending the longest primary to its maximum length by stroking the thumb of the free hand along the shafts of primaries, from base to tip, pressing firmly against the rule all the while (Figure 16.2). It must be emphasized that no attempt must be made to pull the wing straight from the tip; a firm stroking action is required. Small differences in measurement may result from variation in the degree of straightness achieved, but the method reduces errors due to alteration of the lateral curvature during trapping and handling, or occasioned by dampness. It is, however, essential to keep the wing closed and parallel to the long axis of the bird's body.

Ruler with the stop is used. For birds small enough to be measured with a $30 \mathrm{~cm}$ ruler, it is recommended that the wing is measured to the nearest $1 \mathrm{~mm}$ ".

Wing-length maximum chord measurement after Manual of Field Methods (Bairlein, 1995): "Wing length is determined as maximum chord which is the length of the flattened and straightened wing, and it is the distance between the bend of the wing and the longest primary.

Use the ruler with a stop at zero. Read to $0.5 \mathrm{~mm}$. 


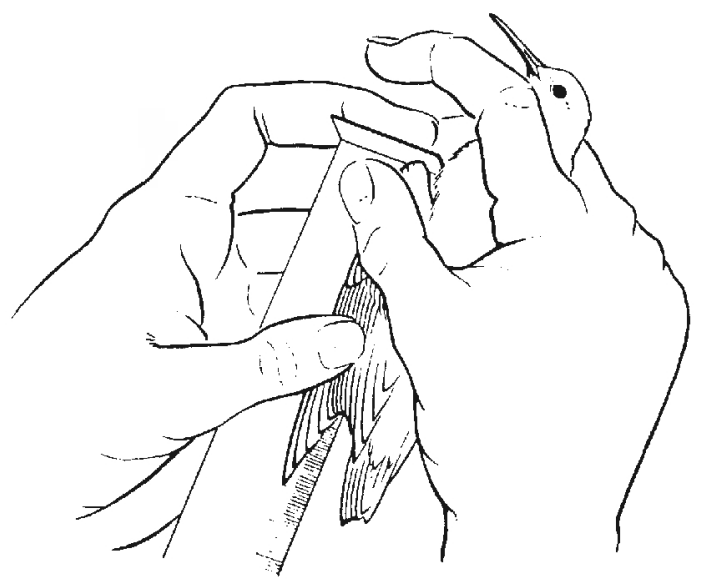

Figure 16.2: Wing-length measurement after Spencer (1972) drawing.

The wing should be folded ("resting position"; Figure 16.3). The wing is then flattened against the ruler with a gentle pressure on the primary coverts with a thumb. The primaries are straightened by pushing the thumb sideways (Figure 16.3B and C) until the primaries are parallel with the ruler. It is also of good help to adjust the position of the primaries with your index (2) or ring finger (3).

Straighten the wing, still flattened against the ruler by strokes with the thumb outwards along the shafts of primaries. Do not move the bend of the wing off the zero stop. Do not use excessive force, and be as cautious as possible to avoid any injures to the fragile wing bones and muscles".

Note that two methods of bird handling are applied in that description.
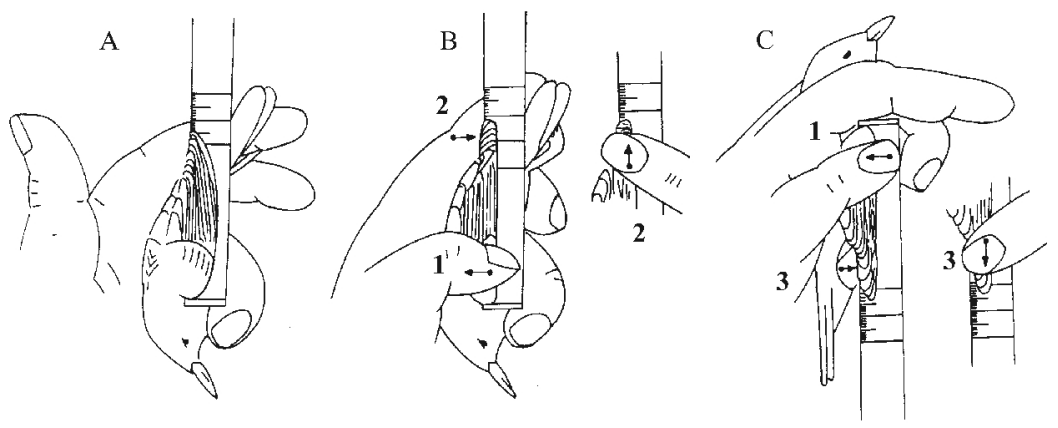

Figure 16.3: Wing-length measurement after drawings by G. Wallinger (from Barlein, 1995). 
Comments. Differences in description of the maximum chord method as presented here, in relation to that recommended as the station standard are derived mainly from the other method of holding bird. The description derived from The Ringer's Manual (Spencer, 1972) is very close to that recommended in the standard description given in the main part of this manual: note the right-hand holding of the bird and position of index finger. Position of index finger here differs from that shown at Figure 16.3C illustrating the measurement given after Manual of the Field Methods (Bairlein, 1995). The position of index finger is important to exact feeling of location of the wing bend in relation to the ruler; the finger tip is most sensitive to feel pressure of the wing bend to the stop of the ruler. Exactness of control of the position of the bend in relation to the ruler is even higher when the ruler without a stop is used. There is a greater possibility to have longer readings when the ruler is placed as it is shown at Figure 16.3C, especially when one has tendency to much pull the primaries along the ruler. The left-hand holding of the bird does not influence the wing-length measurement if this is the only difference from the standard description or the description given in The Ringer's Manual (Spencer, 1972).

Holding the bird with the bill to the wrist, as shown at Figure 16.3 and in Identification Guide to European Passerines (Svensson, 1992), can be commented as in The Ringer's Manual (Spencer, 1972), “... a method of measuring a wing with the bird held in the reverse grip. It is possible to measure equally accurately using this technique, but, it is potentially dangerous if a $30 \mathrm{~cm}$ ruler is used (because of difficulty of controlling both the wing and the heavy rule with one hand), there is nothing to recommend it". In addition, it should be stressed that there is no other measurement, which could be done quickly and precisely enough when this method of the bird holding is used.

Wing-formula measurement. There are two other wing-formula measurement methods, than what is described in this manual, that formally intend to describe a wing-shape.

The method given in Identification Guide to European Passerines (Svensson, 1982): "When studying the wing-formula of a small passerine, it is often helpful to hold the bird in the left hand with the head towards the wrist and with the left wing very slightly spread between the right thumb and index finger. (...)

Make sure that the primaries generally forming the wing-point are not in moult, in which case they may not yet have their full length. Check both wings. When feathers are still growing, you will see generally the glossy, grey or greyish-white feathersheaths at the base of the feathers (or gaps where feathers have been dropped) if the coverts are carefully lifted up with pliers, or by blowing on them. (The sheaths have a bluish tint during the first stages of growth). If one traps a bird with an unusually blunt wing, one should examine the bases of the outermost primaries by lifting up the under wing-coverts and look for remnants of the sheaths. Check also if any feather is accidentally lost or broken before studying the wing-formula. In museum specimens this will often be the case due to shots. 
Gently put the tips of the feathers in order - they may become blunt while the bird is kept in a box or a bag. Make a note if the feathers are much abraded (edge of tips ragged). A heavily worn longest primary can easily be 3-5\% shorter than its full length when fresh. To determine the position of the tip of the second primary, or a notch on the inner web of the second or third, spread the wing as little as possible. When you measure the distance between the tip of a primary or a secondary and the tip of the wing, use either dividers or a ruler (preferably transparent) placed to naturally folded wing, with the scale visible right against the tips (...). Do not measure the individual distances between the tips, a method which will be less accurate if the measurements are summed up. It is advisable to include the distance from the wing-point to the tip of the outermost secondary among these measurements".

Comments. This method is basically the same as our standard wing-formula measurement; it comprises distances between tips of subsequent primaries from the wing-tip. However, the method of the bird handling and measurement technique described do not allow its use for wing-formula differentiation studies on live birds, as it is very inconvenient and extremely time consuming; trials of applying it into the station routine lead consequently to rejecting this very important measurement from the station practice. In practice, it could be used for single individuals when the wing-formula measurement is needed in the identification process, and the method description suggests such use of it. It should be stressed that the comments on checking whether the primaries are not growing are of great importance for any wing-formula measurement.

The method given in Manual of Field Methods (Bairlein, 1995, after Jenni \& Winkler, 1989) and called "wing-shape" measurement has really close to nothing meaning for description of the real wing-shape of the wing treated as a functional unit; it contains several measurements of the length of subsequent flight feathers. Therefore, the description of this measurement is given in the Additional Measurements and Scores section (p. 97).

Tail-length measurement. There are a few methods of tail-length measuring taking the tail-length from the base of rectrices to the tip of the longest one.

The method given in Identification Guide to European Passerines (Svensson, 1982), measurement taken from below the tail: „Start with a moult examination and put the tips of the feathers in order. Preferably use a thin ruler with the scale starting from the outer (very thin or pointed) edge of one end. Place that end under the tail between the tail-feathers and the under tail-coverts and push it gently against the root of the central pair of tail-feathers (...). Measure to tip of the longest tail-feather when the tail is naturally folded".

Another version of the method given in The Ringer's Manual (Spencer, 1972): "Alternatively, dividers may be used, as shown at Figure 16.4. Hold the dividers in the same plane as the tail so that is the side of the point which impinges against the body". 


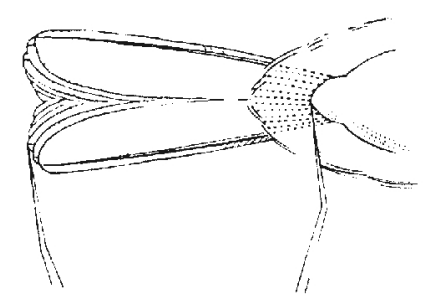

Figure 16.4: Tail-length measurement using dividers after Spencer (1972) drawing.

The above described variants of the measurement taken from the below the tail have their counterparts in such measurements taken from the above of the tail between the tail-feathers and the upper tail-coverts.

Comments. All these methods give different results not only if one compares themselves but also in comparison with the standard method "to the back" described in this manual - so, the method of measurement must be stated. These methods could be a little bit risky to the bird, especially those which manipulate with pointed tools close to the preen gland. The classic method (for skin studies) as described in The Handbook of British Birds (Witherby et al., 1938-41) - use dividers perpendicularly to the tail surface with one divider leg located between central rectrices cannot be used for alive birds as the risk of damage to the preen gland or pygostyl is high.

Fat-scoring. The alternative method of the fat-scoring is recommended in Manual of Field Methods (Bairlein, 1995 after Kaiser, 1993): “The size of the visible fat depot is determined with the use of a 9-grade score (0-8) - Figure 16.5.

Two of the most important fat deposits are checked, the furcular (intraclavicular depression, "tracheal pit") and the abdominal. A specific positioning of the bird's body is necessary to make the determinations.

The bird is laid on its back in one hand, and the legs are held by the other hand. The neck must be stretched slightly so that the furcular deposit is well visible, and the feathers must be blown aside. Legs of the bird should be spread aside, not pulled up or down - it will move the fat.

Additional requirements are (1) the use of bright light, which intensifies the contrast between yellowish fat layers and red muscle tissue, and (2) the determination of the amount of visible fat before the bird is weighed to avoid biasing the measuring process.

The scores from 0 to 8 are taken in the following manner using the subclass description (Table 16.1). At first, estimate the fat class at the furcular region. For example, if the fulcular is "filled", i.e. not concave or convex bulging, the subclass corresponds to $4.00,4.25$ or 4.50 . 


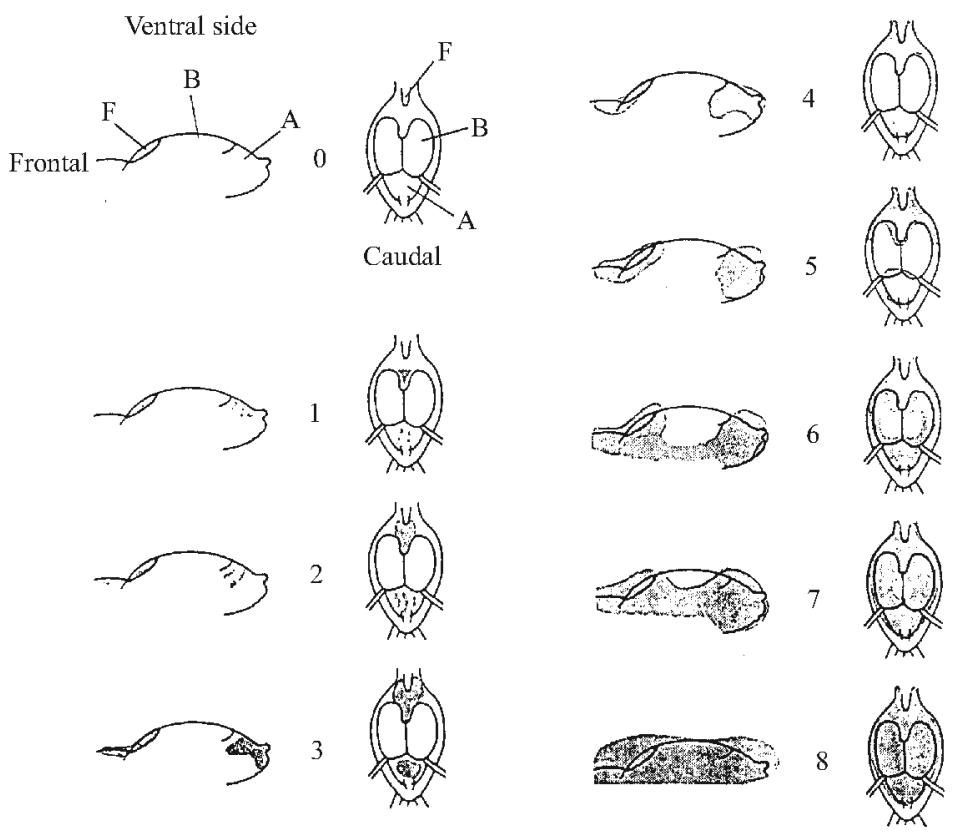

Figure 16.5: Fat scoring after Kaiser, 1993 (from Bairlein, 1995) - compare Table 6.3.

Secondly, check the abdominal area. If the fat deposit covers abdominal structures completely, and the liver is not visible, but the abdominal fat layer is not convex bulging, total score is 4 .

However, some individuals do not follow the process in fat deposition as shown in Figure 16.5. For example, the abdominal area may have a slightly rounded pad of fat with intestinal loops not visible (3.50), while the furcular depression is still not completely covered with fat (1.75). Thus, the average amount of fat score is. 2.6, recorded as main fat score 3.

Use only main fat classes 0 to 8 ".

Comments. The method is based on the same idea as the standard description in this manual. However, description of the subclasses is much more complicated to apply. From the observation of trained people, using the method of averaging the subclasses results in the final main classes being purely theoretical, especially in a hurry, and the results are based on personal judgement depending on one fat deposit only. It was checked because of psychological reasons, one person could believe more the furcular depot while other is more convinced with the abdomenal one. So, the results are less comparable, although derived from the procedure, which seems apparently more precise. 
Table 16.1: Description of the fat classes (from Kaiser, 1993, after Bairlein, 1995).

\begin{tabular}{|c|c|c|c|c|}
\hline Main class & Subclass & Furcular depression & Abdomen & $\begin{array}{l}\text { Colour of the } \\
\text { considered areas }\end{array}$ \\
\hline \multirow[t]{4}{*}{0} & 0.00 & No fat & No fat & Dark red \\
\hline & 0.25 & $\begin{array}{l}\text { Barest trace, very narrow } \\
\text { stripe }\end{array}$ & $\begin{array}{l}\text { Fat deposits not yet deli- } \\
\text { mited }\end{array}$ & \\
\hline & 0.50 & Small stripe & As above & Red \\
\hline & 0.75 & Wedge-shaped & Small trace, patchy & Light red \\
\hline \multirow[t]{4}{*}{1} & 1.00 & Wide wedge & $\begin{array}{l}\text { Trace, very small stripes } \\
\text { around intestinal loops } \\
(\mathrm{mm})\end{array}$ & Light red \\
\hline & 1.25 & $\begin{array}{l}\text { Half of fulcular depression is } \\
\text { covered }\end{array}$ & Trace, stripes $1 \mathrm{~mm}$ wide & Yellow-red \\
\hline & 1.50 & $\begin{array}{l}\text { Almost completely covered } \\
\text { with fat }\end{array}$ & $\begin{array}{l}\text { Trace, stripes smaller than } \\
\text { intestinal loops }\end{array}$ & Yellow-red \\
\hline & 1.75 & $\begin{array}{l}\text { Small amount, almost comple- } \\
\text { tely covered with fat }\end{array}$ & - Wide stripes (2 mm) & Yellowish \\
\hline \multirow[t]{4}{*}{2} & 2.00 & $\begin{array}{l}\text { Completely covered, shape } \\
\text { deeply concave }\end{array}$ & $\begin{array}{l}\text { Slips of visceral fat, area } \\
\text { between intestinal loops } \\
\text { completely filled }\end{array}$ & Light yellow \\
\hline & 2.25 & $\begin{array}{l}\text { Completely covered, shape } \\
\text { deeply concave }\end{array}$ & $\begin{array}{l}\text { Some subcutaneous lipid, } \\
\text { not yet forming pad }\end{array}$ & Light yellow \\
\hline & 2.50 & $\begin{array}{l}\text { Completely covered, shape } \\
\text { deeply concave }\end{array}$ & Very small pad & Light yellow \\
\hline & 2.75 & $\begin{array}{l}\text { Completely covered, shape } \\
\text { deeply concave }\end{array}$ & $\begin{array}{l}\text { Small pad, at least } 2 \text { or } 3 \\
\text { intestinal loops still visible }\end{array}$ & Light yellow \\
\hline \multirow[t]{4}{*}{3} & 3.00 & $\begin{array}{l}\text { Moderate fat reserves cover } \\
\text { ends of interclavicles }\end{array}$ & $\begin{array}{l}\text { Flat pad, one loop still } \\
\text { visible }\end{array}$ & Light yellow \\
\hline & 3.25 & Concave & $\begin{array}{l}\text { Slightly rounded pad, one } \\
\text { loop sometimes visible }\end{array}$ & Yolk-yellow \\
\hline & 3.50 & Still concave & $\begin{array}{l}\text { Slightly bulging, loops } \\
\text { completely covered }\end{array}$ & Yolk-yellow \\
\hline & 3.75 & Almost filled & Bulging, liver visible & Yolk-yellow \\
\hline \multirow[t]{3}{*}{4} & 4.00 & $\begin{array}{l}\text { Filled up to distal portion of } \\
\text { interclavicles }\end{array}$ & $\begin{array}{l}\text { Conspicuously bulging } \\
(2-4 \mathrm{~mm}) \text {, liver sometimes } \\
\text { visible }\end{array}$ & Yolk-yellow \\
\hline & 4.25 & $\begin{array}{l}\text { Filled up to distal portion of } \\
\text { interclavicles }\end{array}$ & $\begin{array}{l}\text { Further increase in bulge } \\
(4-5 \mathrm{~mm}) \text {, liver sometimes } \\
\text { visible }\end{array}$ & Yolk-yellow \\
\hline & 4.50 & $\begin{array}{l}\text { Filled up to distal portion of } \\
\text { interclavicles }\end{array}$ & $\begin{array}{l}\text { Abdominal structures } \\
\text { completely covered, liver } \\
\text { not visible }\end{array}$ & Yolk-yellow \\
\hline
\end{tabular}


continued Table 16.1: Description of the fat classes (from Kaiser, 1993, after Bairlein, 1995).

\begin{tabular}{|c|c|c|c|c|}
\hline Main class & Subclass & Furcular depression & Abdomen & $\begin{array}{l}\text { Colour of the } \\
\text { considered areas }\end{array}$ \\
\hline & 4.75 & $\begin{array}{l}\text { Slightly bulging with central } \\
\text { depression (concave) }\end{array}$ & $\begin{array}{l}\text { Abdominal structures } \\
\text { completely covered and } \\
\text { bulging }\end{array}$ & Yolk-yellow \\
\hline \multirow[t]{3}{*}{5} & 5.00 & Convex bulge & $\begin{array}{l}\text { Extreme convex bulge, } \\
\text { increasing thickness }\end{array}$ & Yolk-yellow \\
\hline & 5.25 & $\begin{array}{l}\text { Just covering flight muscles } \\
\text { from either furc., or abdomen }\end{array}$ & $\begin{array}{l}\text { Extreme convex bulge, } \\
\text { increasing thickness }\end{array}$ & Yolk-yellow \\
\hline & 5.50 & $\begin{array}{l}\text { Covering border of flight } \\
\text { muscles a few } \mathrm{mm}\end{array}$ & $\begin{array}{l}\text { Covering border of flight } \\
\text { muscles a few } \mathrm{mm}\end{array}$ & Yolk-yellow \\
\hline \multirow[t]{3}{*}{6} & 6.00 & $\begin{array}{l}\text { Covering flight muscles by } \\
\text { several } \mathrm{mm}\end{array}$ & $\begin{array}{l}\text { Covering flight muscles by } \\
\text { several } \mathrm{mm}\end{array}$ & Yolk-yellow \\
\hline & 6.50 & \multicolumn{2}{|c|}{ Fat reaches flight muscles from sides of wings } & Yolk-yellow \\
\hline & 6.75 & \multicolumn{2}{|c|}{ Fat covering flight muscles conspicuously } & Yolk-yellow \\
\hline \multirow[t]{4}{*}{7} & 7.00 & \multicolumn{2}{|c|}{ Three quarters of flight muscles covered } & Yolk-yellow \\
\hline & 7.25 & \multicolumn{2}{|c|}{ Large rounded fat-free area in middle of breast } & Yolk-yellow \\
\hline & 7.50 & \multicolumn{2}{|l|}{ Small rounded fat-free area (red) } & Yolk-yellow \\
\hline & 7.75 & \multicolumn{2}{|c|}{ Very small fat-free area still visible } & Yolk-yellow \\
\hline 8 & 8.00 & \multicolumn{2}{|c|}{$\begin{array}{l}\text { Flight muscles not visible, fat layer covers underside/ } \\
\text { ventral side of the bird completely }\end{array}$} & Yolk-yellow \\
\hline
\end{tabular}

